\title{
Gamma-Oryzanol Extraction from Upland Rice Bran
}

\author{
Duangkamol Ruen-Ngam, Chitti Thawai, Raumjit Nokkoul, and Sujitra Sukonthamut
}

\begin{abstract}
Gamma-Oryzanol is one type of antioxidant and has a good effect for health. Gamma-Oryzanol can be fould in rice bran which is the waste from rice milling process. Upland rice is one type of rice which can be grown in the upland area especially in the southern part of Thailand. The upland rice with species of Dawk Pa-yawmhas has been used in this research. There are many ways to extract gamma-oryzanol from rice bran. Maceration is conventional and useable extraction method in gamma-oryzanol extraction. Solvent is one crucial parameter in extraction. Many types of organic solvent such as hexane ethyl acetate acetone isopropanol and ethanol are investigated here. The extraction conditions such as the effect of soaking time, rice and solvent ratio also examined. The highest amount of rice bran oil obtains from acetone as solvent with the ration of rice bran and solvent is 1:4. Moreover the extracted product is also quality checked by HPLC method. The chromatogram clearly shows the peak of gamma-oryzanol.
\end{abstract}

Index Terms_-Dawk Pa-yawn upland rice, Gamma-oryzanol, maceration, rice bran.

\section{INTRODUCTION}

People recently concern and take care of health. Other than meals which they have to take in each day, they will take supplements which compose of useful compounds, such as antioxidant. Antioxidant is found in many types of plants. It's hard to eat a large amount of plants in the same time to achieve the suitable dose and therefore the extraction will be the crucial rule in pulling the important substances through the cell from such plants. The extraction of antioxidant is very important to exclude such important substance from debris. The conventional extraction method is extraction by means of maceration method using different types of organic solvent. Generally this method is used as an elementary method in extracting many valuable compounds [1], [2]. The important parameters which might be affected on amount of obtained substance are the time, the material and the solvent ratio and type of solvent.

There are many types of rice species in Thailand. Dawk Pa-yawm is one type of Thai rice that is grown in the southern part in Thailand. After milling, there is bran which is valuable material left. Rice bran composes of many types of antioxidant compounds, such as tocopherol, tocotrienol, oryzanol, polyphenol, anthocyanin, phytate, etc [3]. Oryzanol is ester compound of ferulic acid and sterol or triterpene alcohol. Oryzanol around 2\% can be found in rice bran and nowadays some group of researches has investigated how to extract this compound from different types of rice [4], [5]. Oryzanol is famous in form of cosmetic ingredient, which

Manuscript received December 31, 2013; revised April 16, 2014

Duangkamol Ruen-Ngam is with the Department of Biology, Faculty of Science, King Mongkut'sInstitute Technology Ladkrabang (KMITL), Bangkok, 10520, Thailand (e-mail: krduangk@kmitl.ac.th, modeliebe@gmail.com). can increase moisture for skin [6]. Moreover oryzanol is known in medical treatment, and oryzanol can reduce cholesterol in blood, reduce gathering of platelet, increase bile in stools, and moderate the activity of disturbed brain [7], [8].

\section{ChEMICALS AND MATERIALS}

Solvent in extraction is hexane, ethyl acetate, acetone, isopropanol and ethanol. Mobile phase with HPLC grade in analysis system is methanol, isopropanol and ethylacetate. All solvents with HPLC grade are bought from Carlo Erba ${ }^{\circledR}$. Dawk Pa-yawn upland rice is obtained from the southern part of Thailand. Gamma-Oryzanol standard is bought from Canta Cruzbiotechnol.

\section{EXPERIMENT PROCEDURE}

The extraction is conducted by maceration method with rice bran and solvent ratios $(\mathrm{g} / \mathrm{g})$ 1:2, 1:4 and 1.6 respectively. The soaking will operate in $250 \mathrm{ml}$ flask with circulation of $200 \mathrm{rpm}$ (called maceration method). The extracting solvents are hexane, ethyl acetate, acetone, isopropanol and ethanol. All experiments will be operated under $30^{\circ} \mathrm{C}$ with 60 minutes soaking time. After extraction, the solvent will be removed by evaporator, then the weight of extracted oil will be weighed by weight machine. All experiments will repeat three times and then calculate average oil percentage compared to the weight of rice branof each condition.

\section{ANALYSIS METHOD}

Quantity data: weight of oil is measured by using weight machine with 4 digits and calculate the rice bran oil percentage as in follow:

Amount of oil or yield oil $(\%)=$

[Weight of oil $(\mathrm{g}) /$ Weight of rice bran $(\mathrm{g})] \times 100$

Quality data: peak of gamma-oryzanolis is analyzed by HPLC. The combination of solvent in mobile phase is methanol:isopropanol:ethylacetate with composition of 47.5:40:12.5 with flow rate $0.5 \mathrm{ml} / \mathrm{min}$. The stationary column is $\mathrm{C} 18\left(\mathrm{ACE}^{\circledR}\right)$. The sample is analyzed at wavelength $330 \mathrm{~nm}$. The report of chromatogram is demonstrated by Shimadzu LCSolution. The peak of gamma-oryzanol is demonstrated at the same retention time of the standard gamma-oryzanol.

\section{RESUlTS AND DisCUSSIONS}

\section{A. Effect of Rice Bran and Solvent Ratio}

Fig. 1 a) - Fig. e) demonstrate that the increasing of the 
rice bran and solvent ratio, the increasing of oil content in the product except in Fig. 1 b). Fig. 1 b) (isopropanol) the amount of oil percentage drop down to around $45 \%$; however, all rice bran and solvent ratios are not significantly different on amount of oil. Almost all extraction solvents increasing the ratio up to 1:4, the oil content reaches to maximum around 55\% and then is stable within the same range of the oil content obtained from the ratio of 1:6 except in Fig. 1 b) and Fig. 1 e) that the discussion will be further discussed in following section. There is a huge error on the result obtained from the rice bran and oil ratio of 1:2 (data from hexane and ethanol) as in Fig. 1 a) and Fig. 1 d) causes to be not significant difference to other ratios. It might occur of trouble in mixing. The ratio with 1:2 cannot penetrate through the rice bran material and the upper liquid level is the same as the solid level and it's hard to remove all or circulate the mixture [9]. Moreover the properties of solvent as boiling temperature might be effective to extraction. As the boiling value demonstrates in Table I [10] that the boiling pointing of hexane and acetone is lower compared to other solvent types, which might evaporate with higher rate and affects to mixing process. Moreover solvent type is also effective the extraction yield and will be discussed in the following section. Above information, because of the minimum of solvent usage, the ratio of 1:4 is better extraction condition compared to $1: 6$.

\section{B. Effect of Solvent Type}

The effect of solvent type on amount of obtained oil shows in Fig. 2 the amount of oil percentage appeared in series of acetone, hexane, ethyl acetate, isopropanol and ethanol. The lowest amount of oil percentage appears in ethanol because of its high polarity. The rice bran oil can be extracted from materials by using both polar solvent (acetone) and non-polar solvent (hexane and ethyl acetate) as results in Fig. 2; however, there is a limitation of solvent whose dielectric constant more than 18 (isopropanol), cannot provide the high value of oil percentage as the properties of other solvents shows in Table I. Other than dielectric constant will affect the amount of oil, viscosity might affect the amount of oil too, as showing the highest viscosity of is opropanol in Table I. This effect will take place in extraction peocess.

\begin{tabular}{|c|c|c|c|c|c|}
\hline $\begin{array}{l}\text { Type of } \\
\text { solvent }\end{array}$ & $\begin{array}{c}\text { Boiling } \\
\text { Point } \\
\left({ }^{\circ} \mathrm{C}\right)^{\mathrm{e}}\end{array}$ & $\begin{array}{c}\text { Dielectric } \\
\text { constant } \\
\left(\varepsilon^{\prime}\right)\end{array}$ & $\begin{array}{l}\text { Surface } \\
\text { tension } \\
(\mathrm{mN} / \mathrm{cm})\end{array}$ & $\begin{array}{c}\text { Viscosity } \\
\text { (cP) }\end{array}$ & $\begin{array}{l}\text { Density } \\
\left(\mathrm{g} / \mathrm{cm}^{3}\right)\end{array}$ \\
\hline a) hexane & 69 & 1.88 & $18.4^{\mathrm{d}}$ & 0.924 & 0.6548 \\
\hline b) isopropanol & 82 & 18 & $23^{\mathrm{c}}$ & $1.96^{\mathrm{a}}$ & 0.786 \\
\hline c) ethyl acetate & 77 & 6.02 & $23.9^{d}$ & $0.426^{\mathrm{a}}$ & $0.897^{\mathrm{b}}$ \\
\hline d) acetone & 56 & 20.7 & 23.7 & 0.32 & 0.791 \\
\hline e) ethanol & 79 & 24.6 & 23.7 & 1.2 & $0.789^{b}$ \\
\hline
\end{tabular}

REMARKS:

Table I is modified from [10]

$$
\begin{array}{lll}
\text { Superscript } & \text { a } & 25^{\circ} \mathrm{C} \\
& \text { b } & 20^{\circ} \mathrm{C} \\
\text { c } & \text { http://www.surface-tension.de/ [11] } \\
\text { d } & \text { http://www.engineering.uiowa.edu [12] } \\
\text { e } & \text { http://en.wikipedia.org/ [13] }
\end{array}
$$

During the process of extraction, the important compound in the rice bran (gamma-oryzanol) dissolves and comes out together with the oil to the both solvent types. Because of gamma-oryzanol structure as it demonstrates the chemical structure in Fig. 3, are both sides of polar and non-polar (ferulic acid and sterol) [14], [15]. Fig. 2 also shows the ability of both hexane and acetone is not significantly different (within the same range of error bar); however, non-polar solvent as hexane is generally used to be extracting solvent [7].

\section{Product Quality}

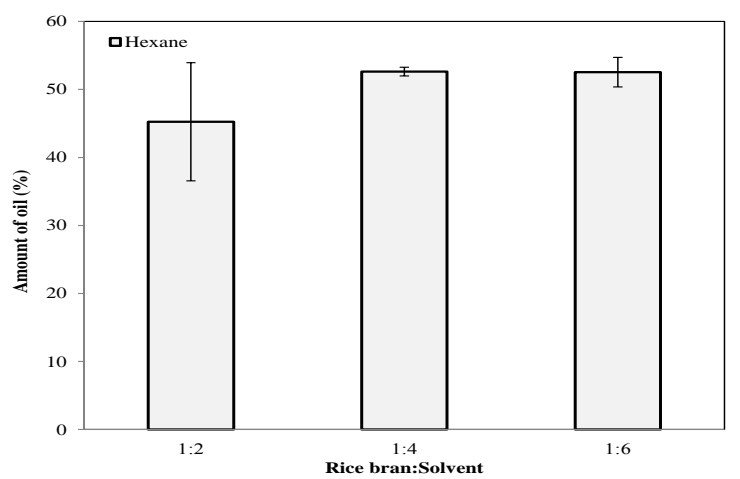

(a)

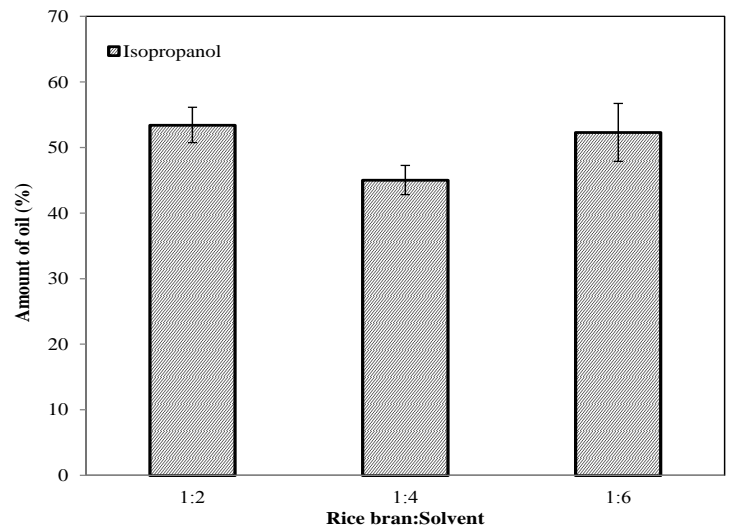

(b)

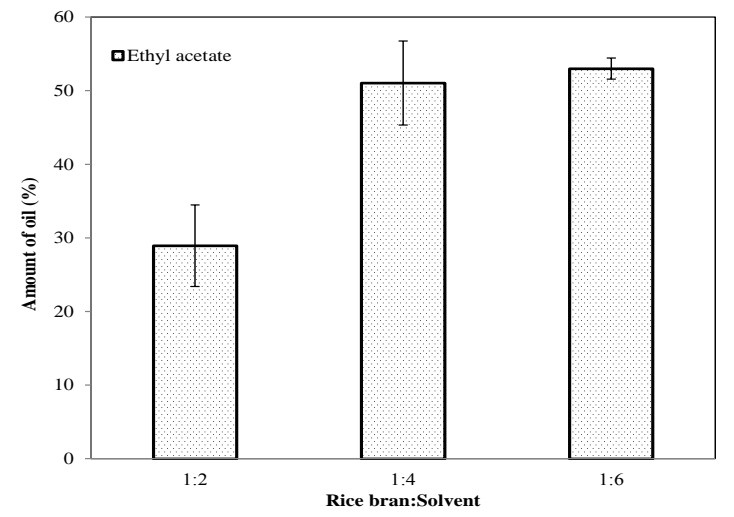

(c)

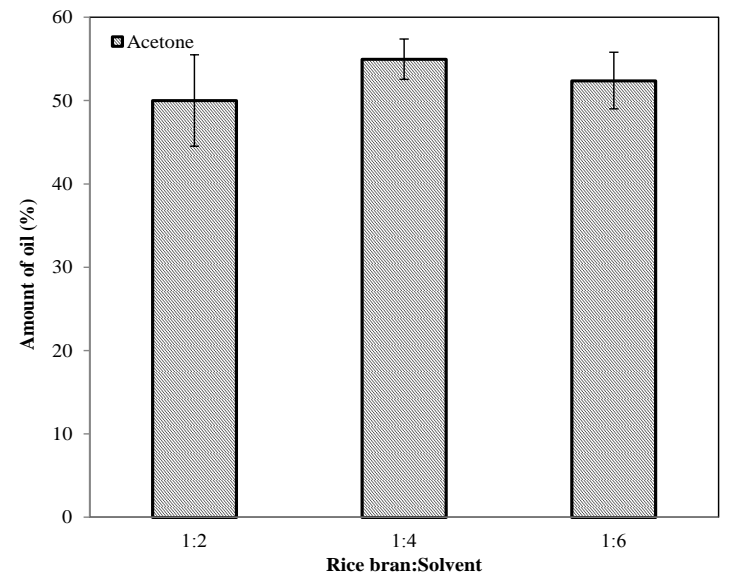

(d) 


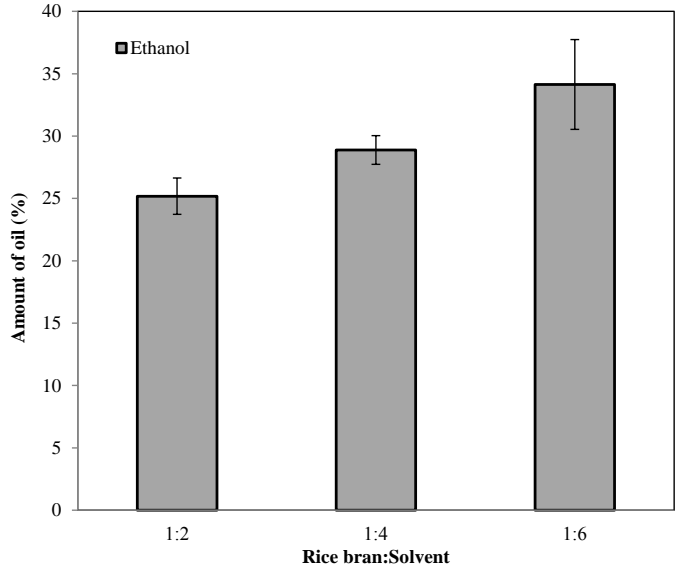

(e)

Fig. 1. Effect of rice bran and solvent ratio in the range of $1: 2$ to $1: 6$ on amount of oil in percentage:a) hexane b) isopropanol c) ethyl acetate d) acetone e) ethanol.

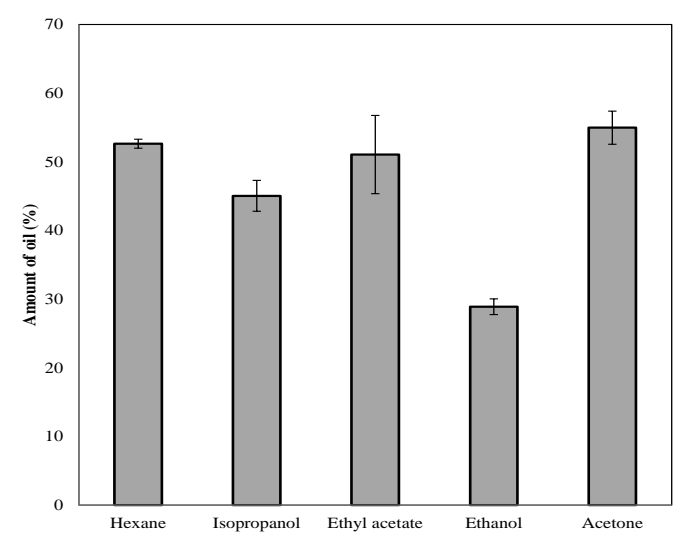

Fig. 2. Effect of solvent type on amount of oil in percentage with the rice bran and solvent ratio of 1:4.
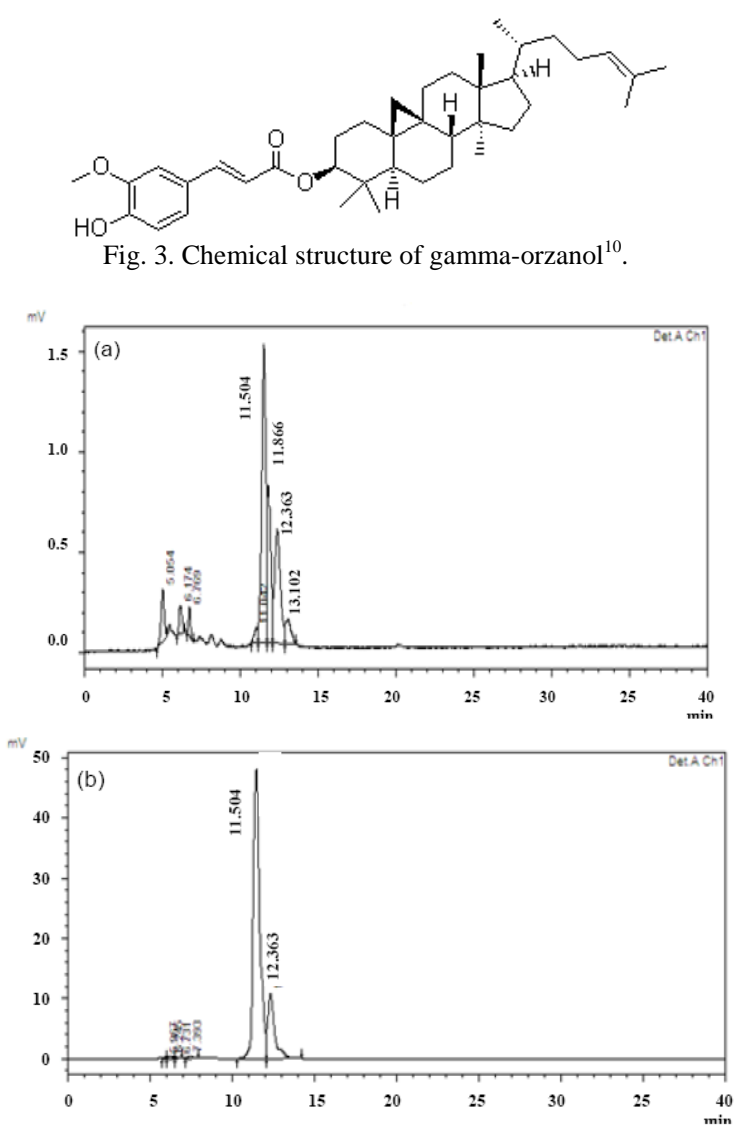

Fig. 4. Chromatogram of a) oil product from rice bran and b) gamma-oryzanol standard.
Product composition is measured by HPLC. The suitable solvent and column is primary investigation prior to check composition of gamma-oryzanol. Both normal-phase and reversed-phase chromatography can use for gamma-oryzanol analysis [16]-[18]. The HPLC columns that can be used for gamma-oryzanol detection are C18 and CN5; however, C18 is used in this case. The chromatogram on Fig. 4 a) will show the product contents with ethanol as extraction solvent and the rice bran and solvent ratio of 1:4. Group of peak product in the extracted is compared to the peak of gamma-oryzanol standard in Fig. 4 b), the peak of product is settled at the retention time of 11.504 and 12.363 minute. Other than two peaks at the same position as standard, there are two peaks at 11.866 and 13.102 minutes that might be checked in further research.

\section{CONCLUSION}

Dawk Pa-yawm is one type of upland rice. The rice bran is considered as the waste from the milling process, which can give antioxidant substance. Gamma-Oryzanol is well known for antioxidant. Maceration method is useable and primary checked for gamma-oryzanol extraction. The best ratio of rice and solvent is 1:4 and three types of solvent namely acetone, hexane and ethyl acetate, which give the same range of the highest amount of oil percentage. The oil product is tested for the peak of gamma-oryzanol and the peak is sharp and appears at the same retention of standard; however, there is some impurity in the product and it should be further purified.

\section{REFERENCES}

[1] D. Ruen-Ngam, A. Shotipruk, and P. Pavasant, "Comparison of extraction methods for recovery of astaxanthin from Haematococcuspluvialis," Separation Science and Technology, vol. 46, pp. 64-70, 2011.

[2] R. Oliveira, V. Oliveira, K. K.Aracava, and C. E. da C. Rodrigues, "Effects of the extraction conditions on the yield and composition of rice bran oil extracted with ethanol-A response surface approach," Food and Bioproducts Processing, vol. 90, pp. 22-31, 2012.

[3] S. Butsat and S. Siriamornpun, "Antioxidant capacities and phenolic compounds of the husk, bran and endosperm of Thai rice," Food Chemistry, vol. 119, pp. 606-613, 2010.

[4] A. Manosroi, W. Ruksiriwanich, M. Abe, H. Sakai, W. Manosroid, and J. Manosroi, "Biological activities of the rice bran extract and physical characteristics of its entrapment in niosomes by supercritical carbon dioxide fluid," Journal of Supercritical Fluids, vol. 54, pp. 137-144, 2010 .

[5] V. R. Pestana-Bauer, R. C. Zambiazi, C. R. B. Mendonça, M. Beneito-Cambra, and G. Ramis-Ramos, " $\gamma$-Oryzanol and tocopherol contents in residues of rice bran oil refining," Food Chemistry, vol. 134, pp. 1479-1483, 2012.

[6] M. J. Lerma-García, J. M. Herrero-Martínez, E. F. Simó-Alfonso, C. R. B. Mendonça, and G. Ramis-Ramos, "Review: Composition, industrial processing and applications of rice bran $\gamma$-oryzanol," Food Chemistry, vol. 115 , pp. 389-404, 2009.

[7] P. Imsanguan, A. Roaysubtawee, R. Borirak, S. Pongamphai, S. Douglas, and P. L. Douglas, "Extraction of $\alpha$-tocopherol and $\gamma$-oryzanol from rice bran," $L W T$, vol. 41, pp. 1417-1424, 2008.

[8] C. Juliano, M. Cossu, M. C. Alamanni, and L. Piu, "Antioxidant activity of gamma-oryzanol: Mechanism of action and its effect on oxidative stability of pharmaceutical oils International," Journal of Pharmaceutics, vol. 299, pp. 146-154, 2005.

[9] M.-H. Chen and C. J. Bergman, "Erratum a rapid procedure for analyzing rice bran tocopherol, tocotrienol and g-oryzanol contents," Journal of Food Composition and Analysis, vol. 18, pp. 319-331, 2005 . 
[10] D. Ruen-Ngam, A. Shotipruk, and P. Pavasant, "Comparison of extraction methods for recovery of astaxanthin from Haematococcus pluvialis," Separation Science and Technology, vol. 46, pp. 64-70, 2011.

[11] Surface-tension. [Online]. Available: http://www.surface-tension.de/

[12] Habdbook of Tables for Applied Engineering Science. [Online]. Available: http://www.engineering.uiowa.edu

[13] Solvent. [Online]. Available: http://en.wikipedia.org/

[14] The look chemicals. [Online]. Available: http://www.lookchem.com/

[15] A. Azrina, I. Maznah, and A. H. Azizah, "Extraction and determination of oryzanol in rice bran of mixed herbarium UKMB; AZ 6807: MR 185, AZ 6808: MR 211, AZ6809: MR 29," ASEAN Food Journal, vol. 15, no. 1 , pp. 89-96, 2008.

[16] J. M. Lerma-García, M. J. Herrero-Martínez, F. E. Simó-Alfonso, B. R. C. Mendonça, G. Ramis-Ramos, "Review Composition, industrial processing and applications of rice bran $\gamma$-oryzanol," Food Chemistry, vol. 115, pp. 389-404, 2009.

[17] Z. Xu and S. J. Godber, "Purification and idenfication of components of $\gamma$-oryzanol in rice bran oil," Journal of Agriultural of Food Chemistry, vol. 47, pp. 2724-2728, 1999.

[18] S. Huang and L. Ng, "An improved high-performance liquid chromatographic method for simultaneous determination of tocopherols, tocotrienols and $\gamma$-oryzanol in rice," Journal of Chromatography. A, vol. 1218, pp. 4709-4713, 2011.

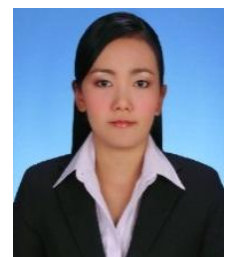

Duangkamol Ruen-Ngam graduated with the bachelor degree from food technology in Faculty of Science, Chulalongkorn University, Thailand. In 2004 she further studied her master course in the field of chemical engineering at Faculty of Engineering in the same university and in 2008 studied the doctoral course which got scholarship from RGJ in Thialand. During the doctoral course, she got a chance to do research

at Kumamoto University, Japan. The special topic is extraction method for antioxidant and solubility in supercritical carbon dioxide. After she got doctoral degree she continued to be postdoctoral research in Kumamoto University, Japan with the special topic hydrothermal treatment of hesperidin. Now she is a lecturer in the Department of Biology, Faculty of Science, King Mongkut's Institute Technology Ladkrabang (KMITL), Bangkok, Thailand. Her research deals with extraction of antioxidant from plant and algae, gamma-oryzanol extraction from upland rice and hydrothermal treatment of plant to provide hydrogen. 